\title{
Duplication and expression of horizontally transferred polygalacturonase genes is associated with host range expansion of mirid bugs
}

Pengjun $\mathrm{Xu}^{1,3+}$, Bin $\mathrm{Lu}^{4 \dagger}$, Jinyan Liu ${ }^{1 \dagger}$, Jiangtao Chao ${ }^{1}$, Philip Donkersley ${ }^{3}$, Robert Holdbrook ${ }^{3}$ and Yanhui $\mathrm{Lu}^{2^{*}}$ (D)

\begin{abstract}
Backgroud: Horizontal gene transfer and gene duplication are two major mechanisms contributing to the evolutionary adaptation of organisms. Previously, polygalacturonase genes (PGs) were independently horizontally transferred and underwent multiple duplications in insects (e.g., mirid bugs and beetles). Here, we chose three phytozoophagous mirid bugs (Adelphocoris suturalis, A. fasciaticollis, A. lineolatus) and one zoophytophagous mirid bug (Nesidiocoris tenuis) to detect whether the duplication, molecular evolution, and expression levels of PGs were related to host range expansion in mirid bugs.

Results: By RNA-seq, we reported 30, 20, 19 and 8 PGs in A. suturalis, A. fasciaticollis, A. lineolatus and N. tenuis, respectively. Interestingly, the number of PGs was significantly positive correlation to the number of host plants $(P=0.0339)$ in mirid bugs. Most PGs (>17) were highly expressed in the three phytozoophagous mirid bugs, while only one PG was relatively highly expressed in the zoophytophagous mirid bug. Natural selection analysis clearly showed that a significant relaxation of selection pressure acted on the PGs in zoophytophagous mirid bugs $(K=0.546, P=0.0158)$ rather than in phytozoophagous mirid bugs $(K=1, P=0.92)$, suggesting a function constraint of PGs in phytozoophagous mirid bugs.
\end{abstract}

Conclusion: Taken together with gene duplication, molecular evolution, and expression levels, our results suggest that PGs are more strictly required by phytozoophagous than by zoophytophagous mirid bugs and that the duplication of PGs is associated with the expansion of host plant ranges in mirid bugs.

Keywords: Polygalacturonase, Gene duplication, Molecular evolution, Expression, Host range expansion

\section{Background}

Horizontal gene transfer (HGT) and gene duplication are two major mechanisms contributing to the evolutionary adaptation of organisms [1-6]. HGT refers to the transfer of genetic materials between species with reproductive isolation, which was first reported more than 70 years ago and has been found to help organisms rapidly adapt to novel environments [1, 7-9]. Gene duplication is one of the main sources of functional

\footnotetext{
* Correspondence: yhlu@ippcaas.cn

${ }^{\dagger}$ Pengjun Xu, Bin Lu and Jinyan Liu contributed equally to this work.

${ }^{2}$ State Key Laboratory for Biology of Plant Diseases and Insect Pests, Institute of Plant Protection, Chinese Academy of Agricultural Sciences, Beijing 100193, People's Republic of China

Full list of author information is available at the end of the article
}

diversity at the genotypic level, contributing to the origin of new genes, the evolution of new gene function, and in certain instances to the evolution of organisms [10-12]. Over the last few decades, these two evolutionary adaptations have been well investigated, but the adaptation by duplication of horizontally transferred genes has rarely been reported.

As one of a group of plant cell wall-degrading enzymes (PCWDEs), polygalacturonase (PG) is ubiquitous in fungi, bacteria, and plants, catalyzing hydrolysis of $\alpha-1$, 4-glycosidic linkages in polygalacturonic (pectic) acid [13]. Interestingly, PGs have also been detected in some insects from Hemiptera and Coleoptera, such as mirid bugs and leaf beetles [14-16]. Biochemically, PGs were first

(c) The Author(s). 2019 Open Access This article is distributed under the terms of the Creative Commons Attribution 4.0 International License (http://creativecommons.org/licenses/by/4.0/), which permits unrestricted use, distribution, and reproduction in any medium, provided you give appropriate credit to the original author(s) and the source, provide a link to the Creative Commons license, and indicate if changes were made. The Creative Commons Public Domain Dedication waiver (http://creativecommons.org/publicdomain/zero/1.0/) applies to the data made available in this article, unless otherwise stated. 
reported in the salivary glands of mirid bugs (Lygus spp.) [17-20]. Subsequently, the genes encoding PG proteins were cloned from mirid bugs and leaf beetles, and phylogenetic analysis suggested these genes were horizontally transferred to mirids from fungi and had undergone multiple duplications $[14,16,21]$. Plants possess cell walls made of complex composite fibers, which prevent insects from feeding on plant nutrients [22]. Thus, the duplication of digestive enzymes (PG genes) was considered as potentially expanding the host plant range of these insects $[14,15]$.

Previously, we demonstrated the duplication of PG genes in Apolygus lucorum [16]. According to host ranges, species in the Miridae (Hemiptera) were divided into two groups: one named phytozoophagy was mainly phytophagous with prey to complementand the other named zoophytophagy was predator which occasionally fed on plant resources) [23, 24]. Thus are an ideal group to test the hypothesis that adaptive evolution of organism by horizontal gene transfer and gene duplication e.g. insects expand their host plant range by PG genes which may have occurred in major phytozoophagous mirid bugs (A. lucorum, Adelphocoris suturalis, A. fasciaticollis and A. lineolatus $[25,26])$ that ancestrally may have been soley predaceous (such as Nesidiocoris tenuis) [27]. Here, we determined the numbers of expressed PG genes in $A$. suturalis, A. fasciaticollis, A. lineolatus and N. tenuis by RNA-seq. We also investigated the expression levels of PG genes in A. suturalis and $N$. tenuis. Our results indicate that the phytozoophagous mirid bugs possessed more PG genes and higher expressed levels of these genes than did the one of zoophytophagous species examined, suggesting that the gene duplication of horizontally transferred PG genes may have been part of what allowed the host range expansion toward mixed phytozoophagy in mirid bugs.

\section{Methods}

\section{Ethics statement}

With permission, we captured the insects in experiment stations of Chinese Academy of Agricultural Sciences. No permits were required for the described insect collection and experimentation.

\section{Insects}

Adults of A. suturalis, A. fasciaticollis, and A. lineolatus were collected from a cotton field at the Langfang Experimental Station of the Chinese Academy of Agricultural Sciences (Hebei Province, China) in 2015. Adults of $N$. tenuis were collected from a tobacco field at the Jimo Experimental Station of the Chinese Academy of Agricultural Sciences (Shandong Province, China) in 2014. Field-collected insects were used for genetic analyses.

\section{Transcriptome analysis}

Compared with nymphs, adults of mirids can feed on a wider diversity of plant species because their ability to fly allows them to move from species to species as plants flower. Therefore, we chose adults to investigate the PG genes in this study. Fifty adults for each group (A. suturalis $=3$ groups, $A$. fasciaticollis $=1$ group, A. lineolatus $=1$ group, and $N$. tenuis $=3$ groups) were used to isolate total RNA with Trizol reagent (Invitrogen, Carlsbad, CA, USA) following the manufacturer's instructions. The cDNA library was constructed, sequenced and analyzed as described by $\mathrm{Xu}$ et al. [28]. Briefly, the mRNA was isolated using Oligo ( $\mathrm{dT}$ ) magnetic beads, broken into short fragments and used to synthesize cDNA. The short fragments were purified with the QiaQuich PCR Purification Kit (Qiagen, Germany) and used to construct the cDNA library. The library was sequenced on an Illumina Hiseq ${ }^{\text {Tm }}$ platform and about 5 gigabase $(\mathrm{Gb})$ of data were generated for each sample, using Majorbio (Beijing, China). Low-quality reads were deleted using Fastx-tools and clean pair-end reads were used for de novo assembly with Trinity (v2.0.6) software [29]. Contigs longer than 200 bases were used for subsequent analysis. The reads from libraries of each species were mapped to the assembled contigs using Bowtie 0.12.7 [30]. The read counts were further normalized as fragments per kilobase of exon model per million mapped reads (FPKM) values [31]. Gene expression profile was estimated using FPKM values by RSEM (v1.1.17) software with default parameters [32]. Unigenes were annotated with blastx BLAST based on the databases of $\mathrm{Nr}$ (NCBI non-redundant protein sequences) (https://www.ncbi.nlm.nih.gov/genbank/ and https://www.ncbi.nlm.nih.gov/protein/), String (Search Tool for the Retrieval of interacting Genes/Proteins) (https://string-db.org/), Swissprot (A manually annotated and reviewed protein sequence database) (http:// www.ebi.ac.uk/uniprot/) and KEGG (Kyoto Encycloedia of Genes and Genomes) (https://www.genome.jp/kegg/) for functional annotation. The e-value cut-off was set at 1e-5 for further analysis.

\section{Identification of PG genes}

To annotate the PGs in the four mirid bugs, 202 coding sequences of PGs were used as query sequences, including 188 coding sequences from Broad Institute (BI), Joint Genome Institute (JGI) and GenBank at National Center for Biotechnology Information (NCBI) [14] and 14 coding sequence from the salivary glands of A. lucorum from our previous work [16]. Then, BLAST was performed for searching PGs. To determine the genomic structure of PGs, we designed primers according to the reference sequences from RNA-seq to amplify PG genes in $N$. tenuis and A. suturalis using DNA as template (Additional file 1: Table S1). 
The PCR program was as follows: $30 \mathrm{~s}$ at $94{ }^{\circ} \mathrm{C}, 30 \mathrm{~s}$ at $55^{\circ} \mathrm{C}$, and $60 \mathrm{~s}$ at $72{ }^{\circ} \mathrm{C}$, for 40 cycles.

Sequence alignment, and phylogenetic/evolutionary analyses Beside our self-sequenced PG genes, we also downloaded PG genes of A. lucorum and Lygus lineolaris from Genbank and then constructed a dataset containing 147 PG genes for subsequent evolutionary analysis. The sequence alignment was performed using the codon model as implemented in PRANK [33]. Phylogenetic analysis was performed using maximum likelihood (ML) method under the GTR + G substitution model [34] with 1000 replicates implemented in RAxML 7.3.2 [35].

\section{Test of selection}

After duplication, genes tended to have a different selective pressure measured as a ratio between synonymous and non-synonymous substitution $(d n / d s)$. To investigate the drive force behind the shift toward plant feeding, we searched for potential selections acting on PG genes in mirids. Here we mainly focus on the transformation between zoophytophagous (N. tenuis) and phytozoophagous (the other mirids). We use an ML approach [36] to test differences in selection pressure between the two feeding habits using the CODEML program implemented in the PAML 4.5 package [37]. We tested whether specific branch models were used to detect positive selection acting on the particular lineages. Four hypotheses were evaluated: (1) one $d_{n} / d_{s}$ ratio for all branches (one-ratio model; assuming that all branches have been evolving at the same rate); (2) $d_{n} / d_{s}$ ratio = 1 for all branches (neutral model; neutral evolution for all branches); (3) zoophytophagous and phytozoophagous lineages have a different $d_{n} / d_{s}$ ratio $\left(\omega_{2}\right.$ and $\omega_{1}$; two ratio model; allowing a foreground branch to evolve under a different rate); and finally (4) neutral evolution for zoophytophagous lineage $\left(\omega_{2}=1\right)$. A likelihood ratio test (LRT) was employed to determine if the alternative model, indicating positive selection, was superior to the null model. The newly developed RELAX method [38], as implemented in the program HYPHY [39], was employed to detect if the relaxation of selective strength occurred at the phytozoophagous and/or zoophytophagous lineage of PG genes and led to loss of function.

\section{Statistics}

Statistical analyses were conducted using Relative valuation and one way ANOVA with SPSS Version 11.0 software package.

\section{Results}

Identification of PGs in four species of mirid bugs by transcriptome analysis

After removing adaptor sequences and low-quality reads, we obtained a total of $23.29,4.51,5.12$, and $26.18 \mathrm{~Gb}$ of clean data in A. suturalis, A. fasciaticollis, A. lineolatus, and $N$. tenuis, respectively. An overview of the sequencing and assembly data are shown (Additional file 1: Table S2 and Additional file 2: Figures S1, S2, S3, S4). The RNA-seq data were submitted to the NCBI Gene Expression Omnibus (GEO) database (accession number: GSE90671) [40], and Sequence Read Archive (SRA) database (accession number: SRR6322944, SRR6322963, SRR6322 964, SRR6322965, SRR6322463, SRR8259282, SRR8259 810, SRR8259912). Using functional annotation, 29,890, $17,879,25,604$, and 39,937 genes $(22.2,30.6,24.5$ and $25.4 \%$ of transcripts) were able to be get BLAST hits using the E-value cutoff and NR database.

With functional annotation and a BLAST search using 202 PGs as reference sequences, we found 30, 20, 19, and 7 PGs in A. suturalis, A. fasciaticollis, A. lineolatus, and $N$. tenuis, respectively (Additional file 1: Table S3-S6). The known host plants of $A$. suturalis, A. fasciaticollis, A. lineolatus, A. lucorum, and $N$. tenuis include 270, 127, 254, 288 and 8 species, respectively [41-43]. It should be noted that without genomes for these species plus transcriptomes from different developmental stages, a thorough phylogenetic analysis will be difficult, because what is missing from the adult transcriptome cannot readily be seen. Previously, 28 PGs were reported in A. lucorum at NCBI, which included 14 PGs we found from the cDNA library [16]. With these data, we analyzed the correlation between the number of host plants and the number of PGs in the five mirid bugs and found a significantly positive correlation $\left(\mathrm{r}^{2}=0.822, \mathrm{~F}=13.82, P=0.0339\right)($ Fig. 1$)$.

\section{Sequence alignment and phylogenetic analysis}

Our phylogenetic tree strongly supported all the PGs in mirid bugs being clustered together (Fig. 2; Bootstrap value =100; Additional file 3), suggesting that the PGs of mirid bugs were derived from fungi and subsequently underwent multiple duplications after horizontally transferring into the genome of mirid bugs. Previously, no more than 50 PGs have been reported. We classified PGs of A. lucorum to six groups according to identities [15]; however, it was difficult to classify them clearly, using more than 100 members from seven species. To determine the gene duplication mode of PGs, we detected the genome structure of seven PGs with complete coding sequence (CDS) by designing primers and amplifying fragments using DNA as templates (six PGs in $A$. suturalis and one PG in N. tenuis), and only one PG in A. suturalis and the PG in $N$. tenuis contained one intron in the open reading frame region (Additional file 2: Figure S5).

\section{Natural selection analysis}

The codeml branch model significantly rejected the neutral evolutionary hypothesis for the whole phylogeny of 


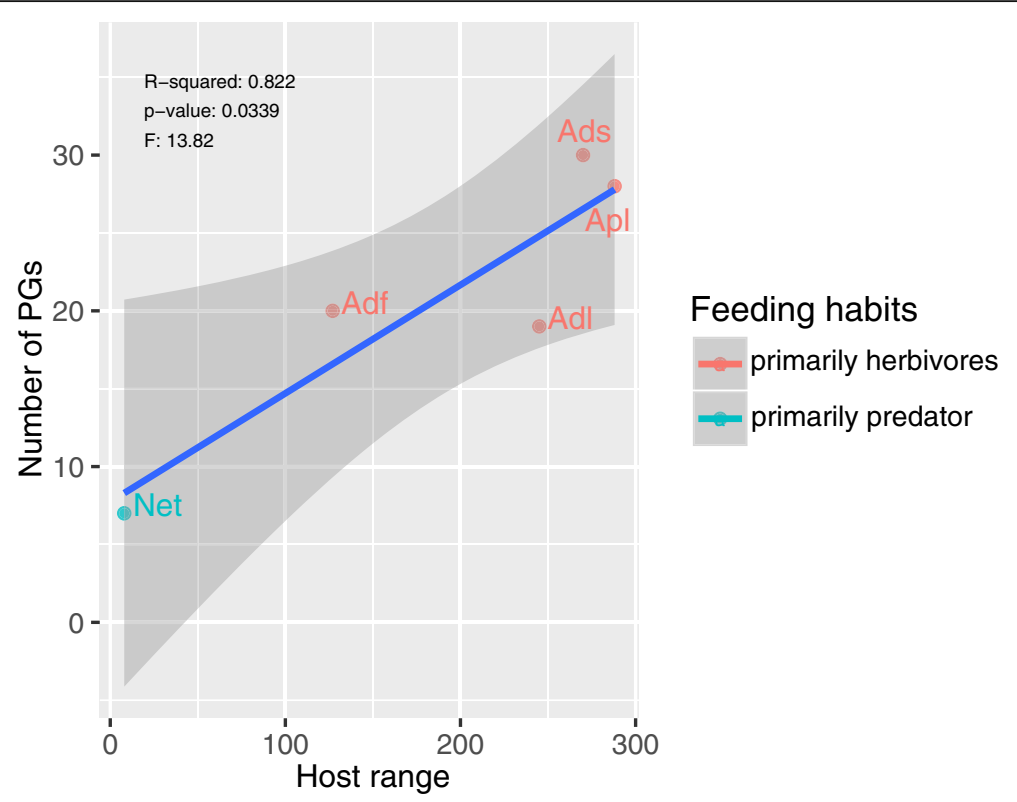

Fig. 1 Correlation between number of polygalacturonase genes (PGs) and host plants. Apl=Apolygus lucorum, Ads = Adelphocoris suturalis, $\mathrm{Adf}=A$. fasciaticollis, $\mathrm{Adl}=A$. lineolatus, $\mathrm{Net}=$ Nesidiocoris tenuis

mirid PGs (Table 1, LRT $=9746.22, p<0.001$ ). Also our analysis suggests that the zoophytophagous lineages, which experienced serious loss of PGs, also evolved according to the non-neutral pattern (LRT $=41.12, P<0.001)$. Given this result, we further specifically tested whether the selection pressure differed between predatory and phytozoophagous mirid bugs. When we set zoophytophagous lineages as foreground and phytozoophagous branches as reference, RELAX estimated the selection intensity parameter value of $\mathrm{K}=0.546$ ( $\mathrm{K}=1$ is RELAX's null hypothesis; $\mathrm{K}<1$, selection pressure been relaxed; $K>1$, selection pressure been intensified), and the alternative relaxation model significantly outperformed the null model with a $P$-value $=$ $1.58 \times 10^{-4}$, which is consistent with the results assessed with the likelihood ratio test. However, this was not the case when we set phytozoophagous lineages as the foreground $(\mathrm{K}=1.0$ and $\mathrm{P}$-value $=0.92)$, which suggest that a relaxation of selection pressures occurred on the zoophytophagous branches.

\section{Expression analysis}

To detect the mRNA level of PGs in phytozoophagous and zoophytophagous mirid bugs, we chose A. suturalis and $N$. tenuis to perform RNA-seq for three replicates (groups) and used the CDS sequence of PGs for counting FPKM value. In A. suturalis, 29 of 30 PGs were highly expressed (average FPKM value $>30$ ) and the expression level of these 30 PGs showed statistically significant differences (d.f. $=29,60, F=11.016, P=6.481 \mathrm{e}-15$ ) (Fig. 3). Only one in seven PGs of $N$. tenuis was highly expressed, but the expression levels were not statistically significant because of big differences among samples (d.f. $=6,14, \mathrm{~F}=2.7757, P=0.05416$ ) (Fig. 4). In $A$. fasciaticollis and $A$. lineolatus, we sequenced one sample per species. As with PGs from the phytozoophagous $A$. suturalis, 17 of 20 PGs A. fasciaticollis and 16 of 17 PGs in A. lineolatus were highly expressed (FPKM value > 30) (Additional file 2: Figures S6, S7).

\section{Discussion}

As barriers to plant nutrients, the diversity of cell walls may promote the adaptive evolution of pests, including insects and pathogenic microbes. Mirid bugs are responsible for serious yield loss in several economically important crops (including cotton and grapes) by causing plant stunting and fruit abscission [44]. To feed on plants, mirid bugs use horizontally transferred PG genes derived from fungi and then multiplied these genes [14, 16]. However, it remains unclear whether the gene duplication of PGs is related to the host range expansion of mirid bugs or not. The PG genes and host-range diversity of species within the family Miridae forms an ideal model to investigate the adaptive evolution of host-shift by horizontally transferred gene duplication [14, 25, 41-43]. Next generation sequencing (NGS) facilitates the investigation of these expressed PG numbers and levels [45].

\section{Identification of PGs in mirid bugs}

In this study, we determined the expressed PG genes in three phytozoophagous and one zoophytophagous mirid bugs by RNA-seq technology. Phytozoophagous mirid bugs usually have a broad host-plant range, while 


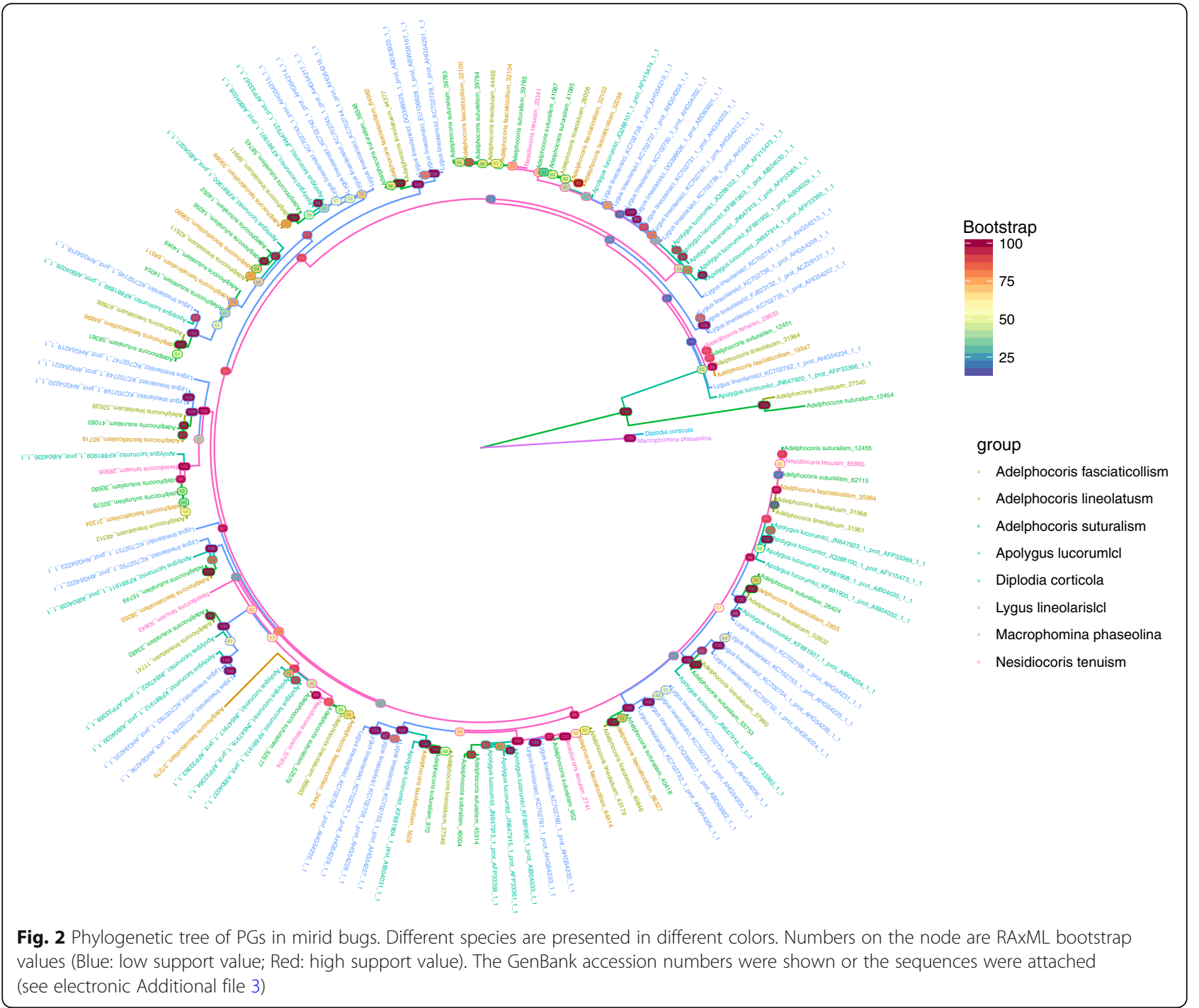

zoophytophagous mirid bugs feed on only a few plants [41-43]. Interestingly, we found a significant, positive correlation between the numbers of host plants and the numbers of expressed PGs in mirid bugs, suggesting the possibility that PG gene duplication may promote host-plant expansion in mirid bugs. There are two sources for gene duplication (DNA and RNA): the first can be explained by three established models: unequal crossing-over, duplicative (DNA) transposition and polyploidization; the second is called retrotransposition, which

Table 1 Selective patterns for PG genes

\begin{tabular}{|c|c|c|c|c|c|c|}
\hline Model & $n p^{a}$ & $\operatorname{Ln~L~}^{b}$ & Estimates of $\omega$ & Models compared & $\mathrm{LRT}^{\mathrm{C}}$ & $P$ Values \\
\hline \multicolumn{7}{|l|}{ Branch model } \\
\hline A: one ratio & 293 & $-59,339.55$ & $\omega=0.10894$ & & & \\
\hline B: one ratio $\omega=1$ & 292 & $-64,212.66$ & $\omega=1$ & B vs. A & 9746.22 & 0.0 \\
\hline C: predacity branches have $\omega_{1}$, the other branches have $\omega_{0}$ & 294 & $-59,339.50$ & $\begin{array}{l}\omega_{1}=0.09379 \\
\omega_{0}=0.10900\end{array}$ & A vs. C & 0.1 & 0.75 \\
\hline D: predacity branches have $\omega_{1}=1$ & 293 & $-59,360.06$ & $\begin{array}{l}\omega_{1}=1 \\
\omega_{0}=0.10798\end{array}$ & D vs. C & 41.12 & 0.0 \\
\hline
\end{tabular}

${ }^{\mathrm{a}}$ Number of parameters

${ }^{\mathrm{b}}$ The natural logarithm of the likelihood value

'Twice the log likelihood difference between the two models 


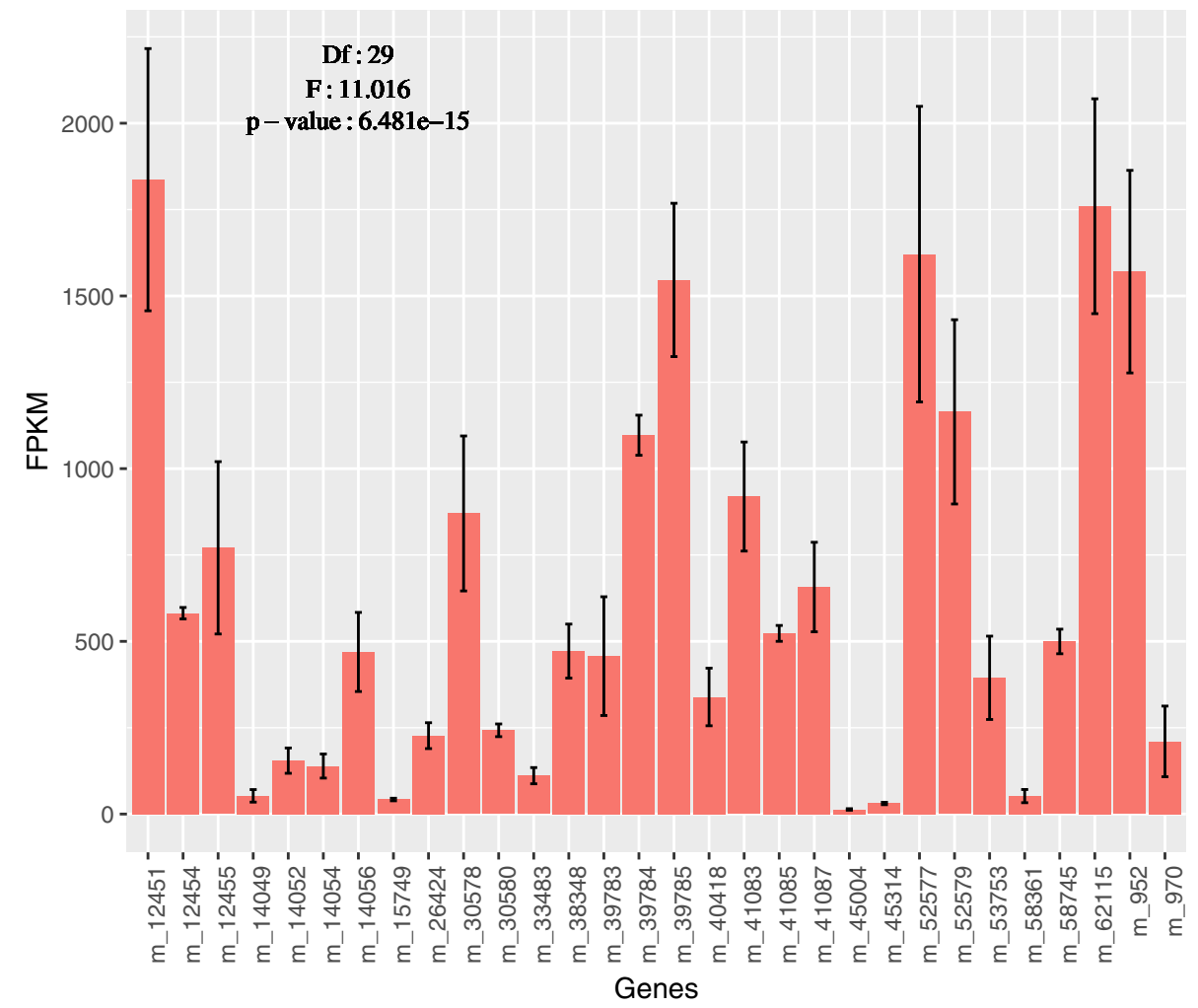

Fig. 3 The expression levels of PGs in Adelphocoris suturalis. The average of FPKM values were more than 5 in the 30 PG genes suggesting a relatively high expression levels of these genes. The FPKM values were used for statistical analysis and the significance was shown. Mean \pm SD

is from mature RNA and without introns $[46,47]$. To determine the duplicated model of PGs, we detected the genomic structure of seven PGs in A. suturalis and N. tenuis. One intron was found in the CDS region of PG in $N$. tenuis. There were no introns in the CDS regions of six PGs. Although we found introns in PGs of mirid bugs, we could not exclude the possibility that the duplication of PGs in mirid bugs derived from retrotransposition.

\section{The molecular evolution of PGs in mirid bugs}

Theoretically, neutral evolution and natural selection drive ecological population divergence and the speciation of organisms [48-50]. As major digestive enzymes of plants, PGs in phytozoophagous mirid bugs might be under more selection pressure than PGs in zoophytophagous bugs. As expected, a test of selection suggested that PGs of mirid bugs were under natural selection but not neutral evolution. Although no positive selection was detected on PGs of phytozoophagous mirid bugs, our results clearly showed significantly relaxed selection in PGs of predators, suggesting a possible loss of function of PGs in zoophytophagous mirid bugs. Molecular phylogeny analysis indicated that zoophytophagous mirid bugs (e.g., $N$. tenuis from the
Bryocorinae) were more ancient than phytozoophagous mirid bugs (e.g., A. fasciaticollis, A. lineolatus, A. suturalis, and $A$. lucorum from the Mirinae), suggesting a host-expansion from zoophytophagous to phytozoophagous mirid bugs [24]. Indeed, phytozoophagous mirid bugs also prey on insects [51]. Taken together, horizontal transfer of PGs from fungi may promote host expansion in mirid bugs: initially, mirid bugs mainly preyed on arthropods and were unable to feed on plants independently but only on plant tissues digested by fungi; subsequently, they obtained PGs from fungi by HGT and gained the capacity to feed on plants independently; finally, phytozoophagous mirid bugs might expand their host-plant ranges by multiplying the number of their PGs, while predatory mirid bugs kept low copy numbers of PGs, which underwent relaxed selection because of the largely non-phytophagous nature of the diet of these species.

\section{Expression patterns of PGs in mirid bugs}

Adaptive evolution at a molecular level includes two mechanisms to regulate gene function: (1) nucleotide/ amino acid sequence variation which could be detected with selection pressure as described above, and (2) 


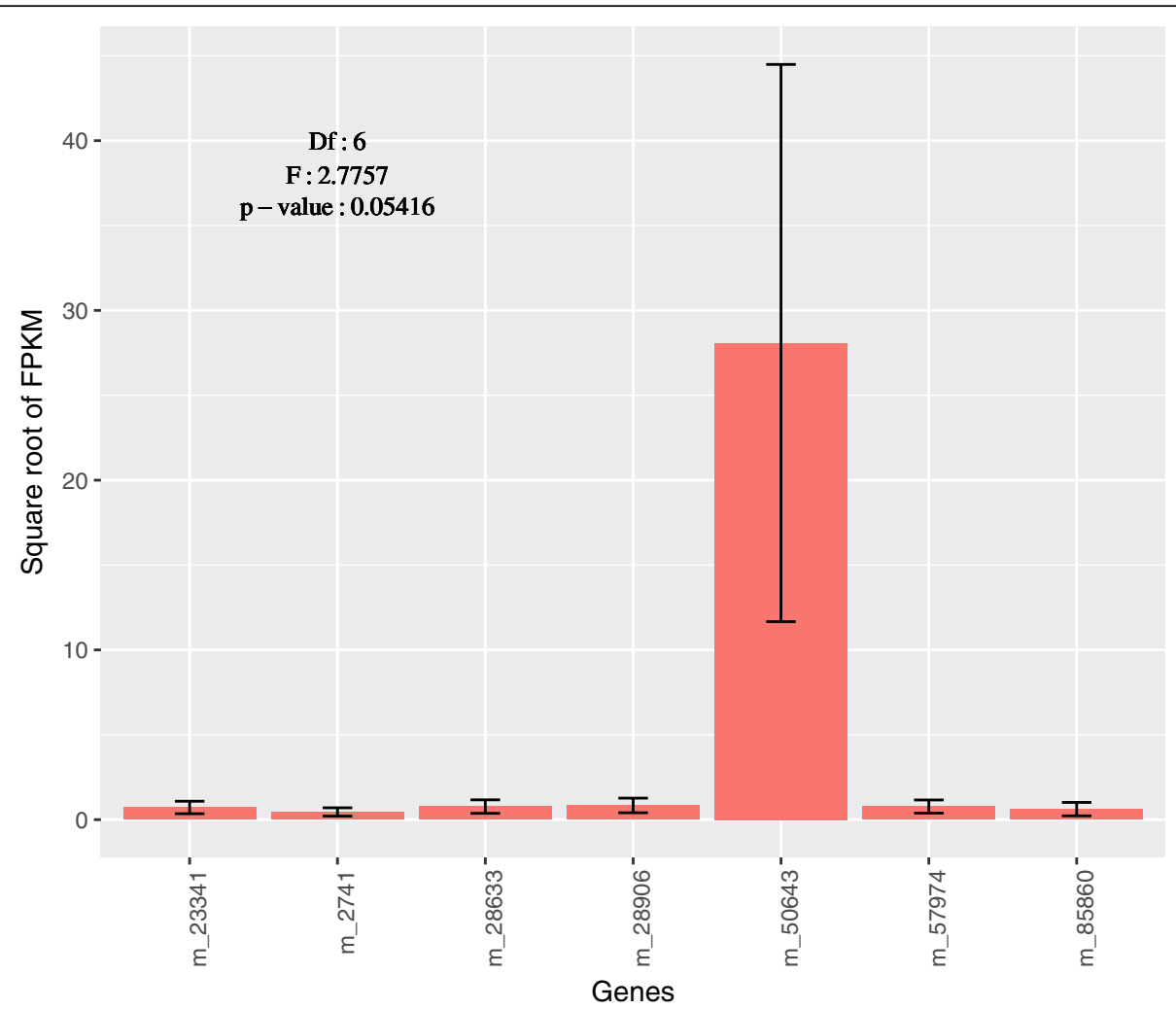

Fig. 4 The expression levels of PGs in Nesidiocoris tenuis. The average of FPKM value of only one in 7 PG genes was more than 5 suggesting only one PG gene was relatively highly expressed in N. tennuis. The square roots of FPKM values were used for statistical analysis. Mean \pm SD

expression levels which are essential for gene function (e.g., opsin evolution in the visual system) [52-55]. To determine whether all PGs are highly expressed and whether the expression levels of PGs were different between phytozoophagous and zoophytophagous mirid bugs, we analyzed the expression levels of PGs in $A$. suturalis (three replicates), N. tenuis (three replicates), $A$. fasciaticollis (no replicates) and A. lineolatus (no replicates) using FPKM values from of RNA-seq. Our results clearly showed that almost all PGs were highly expressed in the three phytozoophagous mirid bugs $(>17)$, but only one PG was relatively highly expressed in zoophytophagous mirid bugs with huge fluctuation, which most likely resulted from that PGs were needed more by phytozoophagous than zoophytophagous mirid bugs. The other reason that feeding on cotton caused the upregulation of PGs could not be completely excluded because the samples used in this study of phytozoophagous mirid bugs were collected in cotton field and the zoophytophagous mirid bugs were collected in tobacco field. Controversially, $N$. tenuis has been used as a natural enemy for pest management because of its zoophytophagy [56-58]. Taking the evidence of molecular evolution together with the mRNA expression levels of PGs, our data support the use of $N$. tenuis as a natural enemy due to the relaxed selection and only one PG expressed in $N$. tenuis, but with controlled density because of occasionally high expression level.

\section{Conclusions}

We identified the number of expressed PGs in three phytozoophagous and one zoophytophagous mirid bug and found a significant, positive correlation between the numbers of PGs and host plants. Natural selection analysis suggested the PGs of zoophytophagous mirid bug were under a significantly relaxed selection. More than 17 PGs were highly expressed in each of the three species of phytozoophagous mirid bugs, but only one PG was relatively highly expressed in predatory mirid bugs. Taken together with evidence of gene copy number, molecular evolution and gene expression levels, our results suggested that PGs were more needed by phytozoophagous than zoophytophagous mirid bugs and the duplication of PGs promoted the host-expansion of mirid bugs. This research suggests that PGs are target genes for the management of phytozoophagous mirid bugs (e.g. RNAi). 


\section{Additional files}

Additional file 1: Table S1. Primers used in this study. Table S2. Summary of the sequence assembly after Illumina sequencing. As $=$ Adelphocoris suturalis, $\mathrm{Af}=\mathrm{A}$. fasciaticollis, $\mathrm{Al}=\mathrm{A}$. lineolatus, $\mathrm{Nt}=$ Nesidiocoris tenuis. Table S3. Identification of polygalacturonase genes in Adelphocoris suturalis. Table S4. Identification of polygalacturonase genes in Adelphocoris fasciaticollis. Table S5. Identification of polygalacturonase genes in Adelphocoris lineolatus. Table S6. Identification of polygalacturonase genes in Nesidiocoris tenuis. (XLSX $24 \mathrm{~kb}$ )

Additional file 2: Figure S1. The discription of RNA-seq in Adelphocoris suturalis. (a) The distribution of sequences length. (b) The E-value distribution of the top matches in the $\mathrm{nr}$ database. (c) The species distribution of the matches in the $\mathrm{nr}$ database. (d) The sequence similarity distribution. Figure S2. The discription of RNA-seq in Adelphocoris fasciaticollis. (a) The distribution of sequences length. (b) The E-value distribution of the top matches in the nr database. (c) The species distribution of the matches in the $\mathrm{nr}$ database. (d) The sequence similarity distribution. Figure S3. The discription of RNA-seq in Adelphocoris lineolatus. (a) The distribution of sequences length. (b) The E-value distribution of the top matches in the nr database. (c) The species distribution of the matches in the $\mathrm{nr}$ database. (d) The sequence similarity distribution. Figure S4. The discription of RNA-seq in Nesidiocoris tenuis. (a) The distribution of sequences length. (b) The E-value distribution of the top matches in the nr database. (c) The species distribution of the matches in the nr database. (d) The sequence similarity distribution. Figure $\mathbf{S 5}$. The genome structure of polygalacturonase gene (m_50643) in Nesidiocoris tenuis. The intron was showed using shade. Figure S6. The expression levels of PGs in Adelphocoris fasciaticollis. Figure S7. The expression levels of PGs in Nesidiocoris tenuis. (DOCX $825 \mathrm{~kb}$ )

Additional file 3: The coding sequence of PGs identified in this study. (ZIP $71 \mathrm{~kb})$

\section{Abbreviations}

BI: Broad Institute; CDS: Coding sequence; FPKM: Fragments per kilobase of exon model per million mapped reads; Gb: Gigabases; HGT: Horizontal gene transfer; JGI: Joint Genome Institute; LRT: Likelihood ratio test; ML: Maximum likelihood; NCBI: National Center for Biotechnology Information; PCWDE: Plant cell wall-degrading enzyme; PG: Polygalacturonase

\section{Acknowledgements}

We thank Wei Li for collecting samples.

\section{Funding}

This study was funded by the National Natural Science Foundation of China (Grant No. 31401752) and the Agricultural Science and Technology Innovation Program (Grant No. ASTIP-TRIC04).

\section{Availability of data and materials}

All sequences are available from GenBank or attached as additional materials (see Additional file 3).

\section{Authors' contributions}

$Y L$ and $P X$ designed this study. $P X, B L, J L$ and $Y L$ performed the experiments and collected data. PX, BL, JL, JC, PD, RH and $Y L$ analysed the data. PX, BL, JL and $\mathrm{YL}$ write the manuscript. All authors read and approved the final manuscript.

\section{Ethics approval and consent to participate}

Not applicable.

\section{Consent for publication}

Not applicable.

\section{Competing interests}

The authors declare that they have no competing interests.

\section{Publisher's Note}

Springer Nature remains neutral with regard to jurisdictional claims in published maps and institutional affiliations.

\section{Author details}

${ }^{1}$ Tobacco Research Institute, Chinese Academy of Agricultural Sciences, Qingdao 266101, People's Republic of China. ${ }^{2}$ State Key Laboratory for Biology of Plant Diseases and Insect Pests, Institute of Plant Protection, Chinese Academy of Agricultural Sciences, Beijing 100193, People's Republic of China. ${ }^{3}$ Lancaster Environment Centre, Lancaster University, Lancaster LA1 4YQ, UK. ${ }^{4}$ Department of Herpetology, Chengdu Institute of Biology, Chinese Academy of Sciences, Chengdu, Sichuan 610041, People's Republic of China.

Received: 22 November 2017 Accepted: 2 January 2019

Published online: 09 January 2019

\section{References}

1. Coll M, Guershon M. Omnivory in terrestrial arthropods: mixing plant and prey diets. Annu Rev Entomol. 2002;47:267-97.

2. Llorens-Mares T, Liu Z, Allen LZ, Rush DB, Craig MT, Dupont CL, Bryant DA Casamayor EO. Speciation and ecological success in dimly lit waters: horizontal gene transfer in a green sulfur bacteria bloom unveiled by metagenomic assembly. ISME J. 2017;11(1):201-11.

3. Magadum S, Banerjee U, Murugan P, Gangapur D, Ravikesavan R. Gene duplication as a major force in evolution. J Genet. 2013;92(1):155-61.

4. Mathers TC, Chen Y, Kaithakottil G, Legeai F, Mugford ST, Baa-Puyoulet $P$, Bretaudeau A, Clavijo B, Colella S, Collin O, Dalmay T, Derrien T, Feng H, Gabaldon T, Jordan A, Julca I, Kettles GJ, Kowitwanich K, Lavenier D, Lenzi P, Lopez-Gomollon S, Loska D, Mapleson D, Maumus F, Moxon S, Price DR, Sugio A, van Muster M, Uzest M, Waite D, Jander G, Tagu D, Wilson AC, van Ooserhout C, Swarbreck D, Hogenhout SA. Rapid transcriptional plasticity of duplicated gene clusters enables a clonally reproducing aphid to colonise diverse plant species. Genome Biol. 2017;18(1):27.

5. Reams AB, Roth JR. Mechanisms of gene duplication and amplification. Cold Spring Harb Perspect Biol. 2015;7(2):a016592.

6. Soucy SM, Huang J, Gogarten JP. Horizontal gene transfer: building the web of life. Nat Rev Genet. 2015;16(8):472-82.

7. Andersson JO. Gene transfer and diversification of microbial eukaryotes. Annu Rev Microbiol. 2009;63:177-93.

8. Keeling PJ, Palmer JD. Horizontal gene transfer in eukaryotic evolution. Nat Rev Genet. 2008:9(8):605-18

9. Tatum EL, Lederberg J. Gene recombination in the bacterium Escherichia coli. J Bacteriol. 1947;53(6):673-84.

10. Innan $\mathrm{H}$, Kondrashov $\mathrm{F}$. The evolution of gene duplications: classifying and distinguishing between models. Nat Rev Genet. 2010;11(2):97-108.

11. Kondrashov FA, Rogozin IB, Wolf YI, Koonin EV. Selection in the evolution of gene duplications. Genome Biol. 2002;3(2):RESEARCH0008.

12. Qian W, Zhang J. Genomic evidence for adaptation by gene duplication. Genome Res. 2014;24(8):1356-62.

13. Markovic $\mathrm{O}$, Janecek $\mathrm{S}$. Pectin degrading glycoside hydrolases of family 28 sequence-structural features, specificities and evolution. Protein Eng. 2001; 14(9):615-31.

14. Kirsch R, Gramzow L, TheißenH G, Siegfried BD, Ffrench-Constant RH, Heckel DG, Pauchet $Y$. Orizontal gene transfer and functional diversification of plant cell wall degrading polygalacturonases: key events in the evolution of herbivory in beetles. Insect Biochem Mol Biol. 2014;52:33-50.

15. Wybouw N, Pauchet $Y$, Heckel DG, Van Leeuwen T. Horizontal gene transfer contributes to the evolution of arthropod herbivory. Genome Biol Evol. 2016;8(6):1785-801.

16. Zhang L, Xu P, Xiao H, Lu Y, Liang G, Zhang Y, Wu K. Molecular characterization and expression profiles of Polygalacturonase genes in Apolygus lucorum (Hemiptera: Miridae). PLoS One. 2015;10(5):e0126391.

17. Strong FE, Kruitwagen EC. Polygalacturonase in the salivary apparatus of Lygus hesperus (Hemiptera). J Insect Physiol. 1968;14(8):1113-9.

18. Agblor A, Henderson HM, Madrid FJ. Characterization of alpha-amylase and polygalacturonase from Lygus spp. (Heteroptera: Miridae). Food Res Int. 1994;27(4):321-6.

19. Frati F, Galletti G, De Lorenzo G, Salerno G, Conti E. Activity of endopolygalacturonases in mirid bugs (Heteroptera: Miridae) and their inhibition by plant cell wall proteins (PGIPS). Eur J Entomol. 2006;103(3):515-22. 
20. Celorio-Mancera M, Greve LC, Teuber LR, Labavitch JM. Identification of endo- and exo-polygalacturonase activity in Lygus hesperus (knight) salivary glands. Arch Insect Biochem Physiol. 2009;70(2):122-35.

21. Allen ML, Mertens JA. Molecular cloning and expression of three polygalacturonase cDNAs from the tarnished plant bug, Lygus lineolaris. J Insect Sci. 2008:8:1-14.

22. Sorensen I, Domozych D, Willats WG. How have plant cell walls evolved? Plant Physiol. 2010;153(2):366-72.

23. Dunning Hotopp JC, Clark ME, Oliveira DC, Foster JM, Fischer P, Munoz Torres MC, Giebel JD, Kumar N, Ishmael N, Wang S, Ingram J, Nene RV, Shepard J, Tomkins J, Richards S, Spiro DJ, Ghedin E, Slatko BE, Tettelin H, Werren $\mathrm{JH}$. Widespread lateral gene transfer from intracellular bacteria to multicellular eukaryotes. Science. 2007;317(5845):1753-6.

24. Jung S, Lee S. Molecular phylogeny of the plant bugs (Heteroptera: Miridae) and the evolution of feeding habits. Cladistics. 2012;28(1):50-79.

25. Lu Y, Qiu F, Feng H, Li H, Yang Z, Wyckhuys KAG, Wu K. Species composition and seasonal abundance of pestiferous plant bugs (Hemiptera: Miridae) on Bt cotton in China. Crop Prot. 2008;27(3-5):465-72.

26. Lu Y, Jiao Z, Li G, Wyckhuys KAG, Wu K. Comparative overwintering host range of three Adelphocoris species (Hemiptera: Miridae) in northern China. Crop Prot. 2011;30(11):1455-60

27. Nakaishi K, Arakawa R. Effects of spiracle-blocking insecticides and microbial insecticides on the predator mirid bug, Nesidiocoris tenuis (reuter) (Heteroptera: Miridae). Pak J Biol Sci. 2011;14(21):991-5.

28. Xu P, Feuda R, Lu B, Xiao H, Graham R, Wu K. Functional opsin retrogene in nocturnal moth. Mob DNA. 2016;7:18

29. Grabherr MG, Haas BJ, Yassour M, Levin JZ, Thompson DA, Amit I, Adiconis X, Fan L, Raychowdhury R, Zeng Q, Chen Z, Mauceli E, Hacohen N, Gnirke A, Rhind N, Palma F, Birren B, Nusbaum C, Lindblad-Toh K, Friedman N, Regev A. Full-length transcriptome assembly from RNA-Seq data without a reference genome. Nat Biotechnol. 2011;29:644-52.

30. Langmead B, Trapnell C, Pop M, Salzberg SL. Ultrafast and memory-efficient alignment of short DNA sequences to the human genome. Genome Biol. 2009;10(3):R25

31. Trapnell C, Williams BA, Pertea G, Mortazavi A, Kwan G, van Baren MJ, Salzberg SL, Wold BJ, Pachter L. Transcript assembly and quantification by RNA-Seq reveals unannotated transcripts and isoform switching during cell differentiation. Nat Biotechnol. 2010:28(5):511-5.

32. Li B, Dewey CN. RSEM: accurate transcript quantification from RNA-Seq data with or without a reference genome. BMC Bioinformatics. 2011:12:323.

33. Löytynoja A, Goldman N. An algorithm for progressive multiple alignment of sequences with insertions. Proc Natl Acad Sci U S A. 2005;102(30):10557-62.

34. Felsenstein J. Confidence limits on phylogenies: an approach using the bootstrap. Evolution. 1985;39(4):783-91.

35. Stamatakis A. Raxml-vi-hpc: maximum likelihood-based phylogenetic analyses with thousands of taxa and mixed models. Bioinformatics. 2006; 22(21):2688-90.

36. Nielsen R, Yang Z. Likelihood models for detecting positively selected amino acid sites and applications to the HIV-1 envelope gene. Genetics. 1998;148(3):929-36.

37. Yang Z. PAML 4: phylogenetic analysis by maximum likelihood. Mol Biol Evol. 2007;24(8):1586-91.

38. Wertheim JO, Murrell B, Smith MD, Kosakovsky Pond SL, Scheffler K. RELAX: detecting relaxed selection in a phylogenetic framework. Mol Biol Evol. 2014:32(3):820-32

39. Pond SL, Frost SD, Muse SV. HyPhy: hypothesis testing using phylogenies. Bioinformatics. 2005;21(5):676-9.

40. Xu P, Song X, Yang X, Tang Z, Ren G, Lu Y. A novel single-stranded RNA virus in Nesidiocoris tenuis. Arch Virol. 2017:162(4):1125-8.

41. El-Dessouki SA, El-Kifl AH, Helal HA. Life cycle, host plants and symptoms of damage of the tomato bug Nesidiocoris tenuis Reut. (Hemiptera: Miridae), in Egypt. J Plant Dis Protect. 1976;83(4):204-20.

42. Pan H, Liu B, Lu Y, Wyckhuys KA. Seasonal alterations in host range and fidelity in the polyphagous mirid bug, Apolygus lucorum (Heteroptera: Miridae). PLoS One. 2015;10(2):e0117153.

43. Pan H, Lu Y, Wyckhuys KA. Early-season host switching in Adelphocoris spp. (Hemiptera: Miridae) of differing host breadth. PLoS One. 2013:8(3):e59000.

44. Lu Y, Wu K, Jiang Y, Xia B, Li P, Feng H, Wyckhuys GY. Mirid bug outbreaks in multiple crops correlated with wide-scale adoption of Bt cotton in China. Science. 2010:328(5982):1151-4.
45. Marguerat S, Bahler J. RNA-seq: from technology to biology. Cell Mol Life Sci. 2010;67(4):569-79.

46. Han MV, Demuth JP, McGrath CL, Casola C, Hahn MW. Adaptive evolution of young gene duplicates in mammals. Genome Res. 2009;19(5):859-67.

47. Kaessmann H. Origins, evolution, and phenotypic impact of new genes. Genome Res. 2010;20:1313-26.

48. Bosse M, Spurgin LG, Laine VN, Cole EF, Firth JA, Gienapp P, Gosler AG, McMahon K, Poissant J, Verhagen I, Groenen MAM, van Oers K, Sheldon BC, Visser ME, Slate J. Recent natural selection causes adaptive evolution of an avian polygenic trait. Science. 2017;358(6361):365-8.

49. Gillespie JH. The status of the neutral theory: the neutral theory of molecular evolution. Science. 1984;224(4650):732-3.

50. Schluter D. Evidence for ecological speciation and its alternative. Science. 2009;323(5915):737-41

51. Li J, Yang F, Wang Q, Pan H, Yuan H, Lu Y. Predation by generalist arthropod predators on Apolygus lucorum (Hemiptera: Miridae): molecular gut-content analysis and field-cage assessment. Pest Manag Sci. 2017;73(3):628-35.

52. Carleton K. Cichlid fish visual systems: mechanisms of spectral tuning. Integr Zool. 2009:4(1):75-86.

53. Fuller RC, Carleton KL, Fadool JM, Spady TC, Travis J. Population variation in opsin expression in the bluefin killifish, Lucania goodei: a real-time PCR study. J Comp Physiol A Neuroethol Sens Neural Behav Physiol. 2004;190(2):147-54

54. Parry JW, Carleton KL, Spady T, Carboo A, Hunt DM, Bowmaker JK. Mix and match color vision: tuning spectral sensitivity by differential opsin gene expression in Lake Malawi cichlids. Curr Biol. 2005;15(19):1734-9.

55. Yokoyama S, Shi Y. Genetics and evolution of ultraviolet vision in vertebrates. FEBS Lett. 2000;486(2):167-72

56. Arno J, Castane C, Riudavets J, Gabarra R. Risk of damage to tomato crops by the generalist zoophytophagous predator Nesidiocoris tenuis (Reuter) (Hemiptera: Miridae). Bull Entomol Res. 2010;100(1):105-15.

57. Sanchez JA, Lacasa A. Impact of the zoophytophagous plant bug Nesidiocoris tenuis (Heteroptera: Miridae) on tomato yield. J Econ Entomol. 2008:101(6):1864-70.

58. Wanumen AC, Sanchez-Ramos I, Vinuela E, Medina P, Adan A. Impact of feeding on contaminated prey on the life parameters of Nesidiocoris tenuis (Hemiptera: Miridae) adults. J Insect Sci. 2016;16(1):103.

\section{Ready to submit your research? Choose BMC and benefit from:}

- fast, convenient online submission

- thorough peer review by experienced researchers in your field

- rapid publication on acceptance

- support for research data, including large and complex data types

- gold Open Access which fosters wider collaboration and increased citations

- maximum visibility for your research: over $100 \mathrm{M}$ website views per year

At $\mathrm{BMC}$, research is always in progress.

Learn more biomedcentral.com/submissions 